\title{
Bio-speckle for microalgae growth monitoring in laboratory scale photobioreactor
}

\section{Bio-Speckle para el monitoreo del crecimiento de microalgas en bio- ensayos a escala de laboratorio}

\author{
G. G. Romero ${ }^{1,2}{ }^{*}$, A. C. Monaldi1 ${ }^{1,2}$, D. O. Dominguez ${ }^{3}$, A. V. Blanc ${ }^{1,2}$, L. Moraña ${ }^{4}$ \\ 1. Universidad Nacional de Salta- Facultad de Ciencias Exactas, Grupo de Óptica Láser \\ 2. INENCO-CONICET \\ 3. Universidad Nacional de Salta- Facultad de Ingeniería, Grupo de Óptica Láser \\ 4. Universidad Nacional de Salta- Facultad de Ciencias Naturales, Laboratorio de Calidad de Aguas \\ (*) E-mail: romeropelayog@gmail.com
}

Received: 01/12/2016 Accepted: 29/05/2017

DOI: $10.7149 /$ OPA.50.2.49033

\begin{abstract}
:
Microalgae are widely used in different industries - pharmaceutical, cosmetic, in those dealing with pollution prevention, aquaculture and especially biofuels. Because of the wide range of use, there is an active interest in microalgae large-scale cultivation. Standard techniques for algae biomass production requires cultivation in nutritious culture media, and well-defined external parameters, such as controlled conditions of light intensity, temperature and aeration gas. Commercial production of microalgae is expensive, and the addition of nutrients in culture media contributes to its high cost. The evaluation of the quality of culture media using wastewater effluents or agro-industrial waste can be a way to reduce algal cultures costs. This research aims to develop a noninvasive method for the testing of effectiveness of agro-industrial waste, previously treated, as culture media through daily monitoring of population increase microalgae. We found that it is possible to detect the growth of the microorganisms by using statistical cumulants as numerical approaches for analyzing the dynamic speckle patterns produced by samples of Chrorella Vulgaris algae cultivated in bold basal culture medium.
\end{abstract}

Key words: Biospleckle, microalgae growing, speckle activity, autocorrelation function, optical density.

RESUMEN:

Las microalgas, son ampliamente utilizadas en las industrias farmacéutica, cosmética, en aquellas relacionadas con la prevención de contaminación, acuacultura y especialmente en biocombustibles. Debido a su amplio rango de aplicaciones existe un gran interés en el cultivo de microalgas a gran escala. Las técnicas estándar para la producción de biomasa algal requieren de su cultivo en medios nutritivos y parámetros externos bien definidos tales como condiciones controladas de iluminación, temperatura y aireación. La producción comercial de microalgas es costosa y la adición de nutrientes a los medios de cultivos contribuye a aumentar el costo. La evaluación de la calidad de medios de cultivos usando aguas residuales o residuos agroindustriales puede resultar en una vía para reducir costos. Este trabajo tiene por objetivo el desarrollo de un método no invasivo para monitorear la eficiencia de residuos agroindustriales, previamente tratados, como posibles medios de cultivos a través del monitoreo diario del crecimiento poblacional de las microalgas. Hemos encontrado que es posible detectar el crecimiento de los microorganismos usando cumulantes estadísticos como una aproximación numérica para analizar la actividad de patrones de speckle dinámico producidos por muestras de algas Chrorella Vulgaris cultivadas en medio basal Bold.

Palabras clave: Biospleckle, crecimiento de microalgas, actividad de speckle, función de autocorrelación, densidad óptica. 


\section{REFERENCES AND LINKS / REFERENCIAS Y ENLACES}

[1] H. Rabal, M. Trivi, R. Arizaga, N. Cap, G.Romero, E. Alanís, "Transient phenomena analysis using dynamics speckle patterns," Opt. Eng. 38(1), 57-62 (1996). https://doi.org/10.1117/1.600789

[2] G. Romero, E. Alanís, H. Rabal, "Statistics of the dynamics speckle produced by rotating diffuser and its application to the assessment of paint drying," Opt. Eng. 39(6), 1652-1658 (2000). https://doi.org/10.1117/1.602542

[3] I. Yamaguchi, M. Yokota, T. Ida, M. Sunaga, K. Kobayashi, "Monitoring of Paint Drying Process by Digital Speckle Correlation,” Op. Rew. 14 (6) 362-364 (2007). https://doi.org/10.1007/s10043-007-0362-0

[4] Y. Aizu, T. Asakura, "Bio-speckle phenomena and their application to the evaluation of blodd flow," Opt. Laser Technol. 23, 205-219 (1991). https://doi.org/10.1016/0030-3992(91)90085-3

[5] A. Oulomara, G. Tribillon, J. Douvernoy, "Biological activity measurements on botanical specimen surfaces using a temporal decorrelation effect of laser speckle," J. Mod Opt. 36, 165-179 (1985). https://doi.org/10.1080/09500348914550221

[6] A. Kurenda, A. Adamiak, A. Zdunek, "Temperature effect on apple biospeckle activity evaluated with different indices," Postharvest Biol. Technol. 67, 118-123 (2012). https://doi.org/10.1016/i.postharvbio.2011.12.017

[7] B. Ruth, "Blood Flow determination by the laser speckle method," Int. J. Microcirc. Clin. Exo. 9, 21-5 (1990).

[8] M. Pajuelo, G. Baldwin, H. Rabal, N. Cap, R. Arizaga, M. Trivi,"Bio-speckle assessment of bruising in fruits," Opt. Las. Eng. 40, 13-24, (2003). https://doi.org/10.1016/S0143-8166(02)00063-5

[9] G. F. Rabelo, A. Machado Enes, R. A. Braga Jr, I. M. Dal Fabbro, "Frequency response of biospeckle laser images of bean seeds contaminated by fungi," Biosystems Engineering 110(3), 297-301(2011). https://doi.org/10.1016/j.biosystemseng.2011.09.002

[10] G. G. Romero, C. C. Martinez, E. E. Alanís, G. A Salazar, G. V. Broglia, L. Alvarez, "Bio-speckle activity applied to the assessment of tomato fruit ripening," Biosystems Engineering, 103, 116-119 (2009) https://doi.org/10.1016/j.biosystemseng.2009.02.001

[11] H. J. Rabal, R. A. Braga Jr eds, Dynamic Laser Speckle and Applications. CRS Press, J. Taylor and Francis Publisher. (Boca Ratón, FL, USA) (2009).

[12] M. A. Borowitzka, "Commercial production of microalgae: ponds, tanks, tubesand fermenters," J. Biotech. 70, 313-321(1999). https://doi.org/10.1016/S0168-1656(99)00083-8

[13] P. Vishwanath, T. Kallqvist, E. Olsen, G. Vogt, H. R. Gislerød, "Fatty acid composition of 12 microalgae for possible use in aquaculture feed," Aquacult Int 15, 1-9 (2007). https://doi.org/10.1007/s10499-006-9060-3

[14] V. Makarevičienè, V. Andrulevičiūtè, V. Skorupskaitè, J. Kasperovičienè, "Cultivation of Microalgae Chlorella sp. and Scenedesmus sp. as a Potentional Biofuel Feedstock," Env. Res. Eng. and Management, 3(57), 21 - 27 (2011).

[15] N. Munir, A. Imtiaz, N. Sharif, S. Naz, "Optimization of growth conditions of different algal strains and determination of their lipid contents," J. An. \& Plant Sc., 25(2), 546-553 (2015).

[16] A. M. Sharma, P. K. Sahoo, S. Singhal, A. Patel, "Impact of various media and organic carbon sources on biofuel production potential from Chlorella spp.," 3 Biotech 6, 116 (2016). https://doi.org/10.1007/s13205-016-0434-6

[17] A. E. Marchello, A. T. Lombardi, M. J. Dellamano-Oliveira, C. W. O. De Souza, "Microalgae population dynamics in photobioreactors with secondary sewage effluent as culture medium," Braz J Microbiol. 46(1), 75-84 (2015).

[18] B.O. Arredondo Vega, B. Cordero Esquivel, C. Herrero, J. Abalde, Manual de Técnicas Bioquímicas Aplicadas en Ficología. CISESE, Universidad de la Coruña, España (1997).

[19] B.O. Arredondo Vega, D. Voltolina, eds, Métodos y herramientas analíticas en la evaluación de biomasa microalgal. CIBNOR. (2007).

[20] H. W. Bischoff, H. C. Bold. Phycological Studies. IV. Some Algae from Enchanted Rock and Related Algae Species. University of Texas Publications (1963).

[21] R. A. Braga Jr., B. O. Silva, G. Rabelo, R. M. Costa, R. M. Enesa, N. Cap, H. J. Rabal, R. Arizaga, M. Trivi, G. Horgand, "Reliability of biospeckle image analysis," Opt. Laser Eng. 45, 390-395 (2007).

https://doi.org/10.1016/j.optlaseng.2006.07.002 
[22] R. Kruger, W. Thompson, A. F. Turner, “Computer diagnosis of pneumoconiosis," IEEE Transc, Sys., Man Cybern 4, 40-50 (1974). https://doi.org/10.1109/TSMC.1974.5408519

[23] G. Rabelo, R. Braga Jr, I. Fabbro, M. Trivi, H. Rabal, R. Arizaga, "Laser speckle techniques in quality evaluation of orange fruits," Revista Brasileira de Engenharia Agrícola e Ambiental 9(4), 570-575 (2005).

https://doi.org/10.1590/S1415-43662005000400021

\section{Introduction}

Dynamic speckle phenomenon occurs when laser light is scattered by bodies exhibiting some activity, as biological material or local fluctuations in the dielectric constant of a medium does. Scattered light is frequency (Doppler) shifted from the incident laser light frequency due to rotational, translational, and internal motion of the scattering species. The visual appearance of such a phenomenon is similar to a surface of a boiling liquid, originating the denomination of dynamical speckle, boiling speckle or biospeckle. Speckle activity has been extensively studied and as results of several research projects in Optics a wide variety of parameters and methodologies for measuring the activity of such kind of speckle patterns have been proposed. In literature a wide range of applications are reported, from industrial applications like paint drying monitoring [1-3] to physiological activity of living objects such as blood flow, heartbeat, viability of seeds, maturity and bruising in fruits among others [4-10]. The metrological uses of dynamic speckle well consolidated by systematic testing of all the approaches arising by the many applications [11] suggest that it can be used as a tool for monitoring cultivation of microalgae in laboratory scale photobioreactor.

Microalgae are widely used in different industries - pharmaceutical, cosmetic, in those dealing with pollution prevention, aquaculture and especially biofuels [12-16]. Microalgae use sunlight, various nutrients and $\mathrm{CO}_{2}$ to synthesize biomass, biomolecules and metabolites of economic importance as a source of food, medicine, fodder, fertilizers and biofuels. Because of the wide range of use, there is an active interest in microalgae large-scale cultivation. Commercial production of microalgae is expensive, and the addition of nutrients in culture media contributes to its high cost. The evaluation of the quality of culture media using wastewater effluents or agro-industrial waste can be a way to reduce algal cultures costs. In this sense, bioassays at laboratory scale and field are important in order to test microalgal biomass production using agro-industrial effluents as nutrients [17].

In the present study, the technique used in a biological lab to investigate the efficiency of agro-industrial effluents as culture media, can be summarized in the cultivation of microalgae in photobioreactors and a daily monitoring to investigate the growth performance of the specimens. The growth of microalgae culture is expressed as the increase in biomass calculated for a period of time or a specific growth phase [18]. This increase can be estimated by different methods, such as cell count under the microscope, the determination of changes in culture by optical density measured in spectrophotometer or the quantification of biomass dry weight, total or organic. From all these methods, the cell count is the most widely used for being the simplest and inexpensive [19]. The disadvantage of using the latter method, which is time consuming at microscope and must be performed by trained technicians. It is important; therefore, investigate alternative methodologies to monitoring microalgae in large scale, quickly and easily.

In this interdisciplinary work we propose the use of bio-speckle technique, as a starting point to develop a non-invasive sensor, since it would allow in the future the determination of algal population growth "in situ"; this is without extracting the samples from the photobioreactor, facilitating the daily monitoring. Results obtained from the Time History of the Speckle Patterns (THSP) [5], of samples of Chrorella Vulgaris cultivated in bold basal culture medium (BBM) [20], by means statistical cumulants [23] are presented and are compared with those obtained by standard measurements used commonly in biology labs. 


\section{Materials and methods \\ 2.a. Bio-speckle techniques}

As in our experiments light passes through the samples, the optical arrangement is the typical one used in forward-scattering speckle. Figure 1 shows a layout of the experimental set-up for acquiring intensity fluctuations of dynamical speckle patterns. The samples, placed in prismatic acrilic containers of $1 \mathrm{~cm}$ thick with the side facing the CCD unpolished, are illuminated whith a Ar-Kr tunable laser.

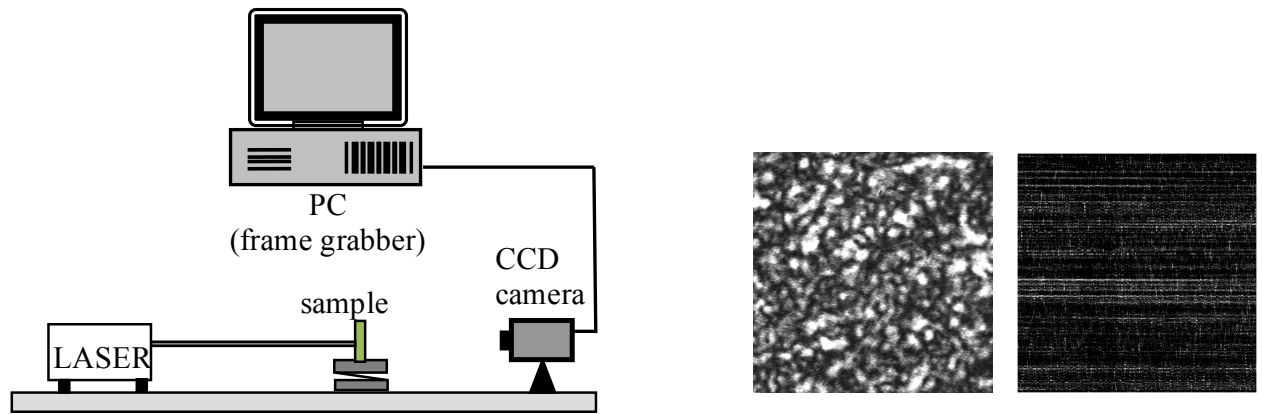

Fig. 1. Experimental set-up for THSP images acquisition.

The CCD camera captured speckle images at a rate of 25 frames per second. For each state of the phenomenon under study, 512 successive images of the dynamic speckle pattern were taken and a fixed column of each image (i.e. the central column) was grabbed. With these 512 columns, an image of $512 \times 512$ pixels was built and digitized in 256 gray levels. This resulting image is the so called Time History of the Speckle Pattern (THSP), where each row represents the time evolution of the light intensity at a given point of the speckle field. The activity of the sample appears as intensity fluctuations in the horizontal direction. Images of instantaneous speckle pattern and THSP typicals are shown in the insets of Figure 1.

The samples where illuminated by four wave length, 483, 514, 647 and $676 \mathrm{~nm}$, in order to investigate the dependence of the speckle activity with $\lambda$ and to compare with the OD commonly used in biology labs as parameter for monitoring the growth of the algal strains. The choice of these particular wave lengths, plus the availability, was based on the properties of the interaction of light with biological tissues. In our particular case, due to the high chlorophyll content of algae, red wavelengths (647 and 676) are highly absorbed, in opposition to the green $(514 \mathrm{~nm})$ which is reflected. Whilst that, $\lambda=483 \mathrm{~nm}$ is very close to the absorption peak of b-chlorophyll and other important components such as carotenoids.

The intention of this research is to encounter an optimal measurement of bio-speckle activity that could be associated with the increase of algal strains. A well-defined and widely used parameter in literature, such as the mean life time of speckle grains [10] was tested. This numerical approach, the most popular for measuring motility of scatters in biological and non biological objects, briefly consists in the approximation of the autocorrelation function applied in a time history of the speckle pattern (THSP) by means of statistical cummulants. The autocorrelation function of each THSP row is given by,

$$
G(\tau)=\langle I(t) I(t+\tau)\rangle
$$

where $\tau$ is the lag time and the bracket represents the ensemble average, is calculated. From these results, the average autocorrelation is obtained. The activity of the speckle diagrams is measured adjusting the average autocorrelation function by using a function such as:

$$
G(\tau)=a+(1-a) \exp \left[-\left(b_{1} \tau+b_{2} \tau^{2} \ldots+b_{n} \tau^{n}\right)\right] ;
$$

where $b_{i}$ being associated with statistical cummulants [10] and are used as a measure of the speckle activity.

\section{2.b. Samples preparation}

In Fig. 2, an image of the experimental set up of microalgae cultivation system is shown. Basically, it consisting of photobioreactors (shake flasks) of $600 \mathrm{ml}$ capacity. In each of them, Chlorella Vulgaris is cultured in $500 \mathrm{ml}$ BBM medium, until an initial concentration of $5000 \mathrm{ind} / \mathrm{ml}$ is reach. Three replicas were performed and placed randomly on the shelves of the culture chamber under constant light (fluorescent lamps of $72 \mathrm{~W}$ ), temperature of $24 \pm 1{ }^{\circ} \mathrm{C}$ and constant aeration. 


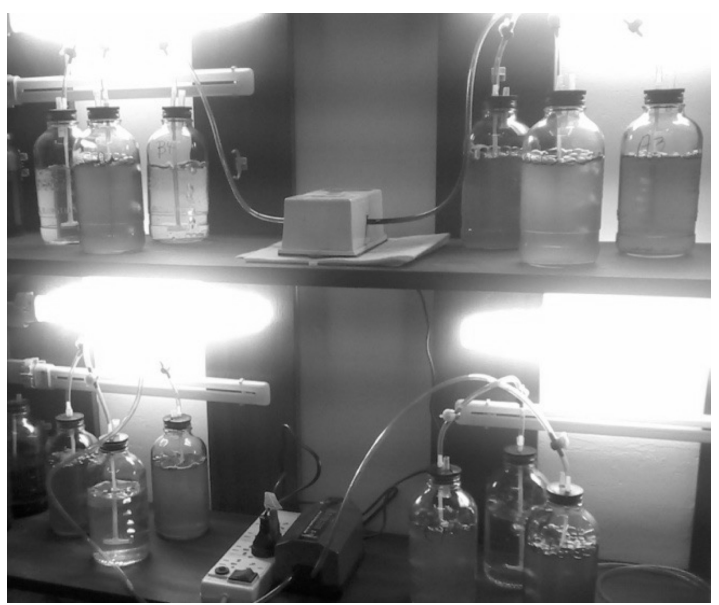

Fig. 2. Laboratory photobioreactors.

Data cell concentration of microalgae is accomplished by measuring the optical density (OD) at four wavelengths $(676 \mathrm{~nm}, 647 \mathrm{~nm}, 514 \mathrm{~nm}$ and $483 \mathrm{~nm})$ in a spectrophotometer HACH DR 5000.

\section{Experimental Results}

\section{3.a. Calibration Experiment}

In this study, and for the purpose of calibrating the measurement methodology using bio-speckle techniques, the population growth of Chlorella Vulgaris, seeded in BBM culture, is daily monitored. As illustration in Figure 3 a), OD curves for each sample versus time and for $\lambda=483 \mathrm{~nm}$ are shown. As seen from this figure, the OD temporal variation of each sample is different, except for the first day where the number of algae is approximately the same for all photobioreactores. This dispersion is consistent with the fact that inevitably experimental culture conditions, namely temperature, light intensity or aeration, vary slightly from one photobioreactor to another.
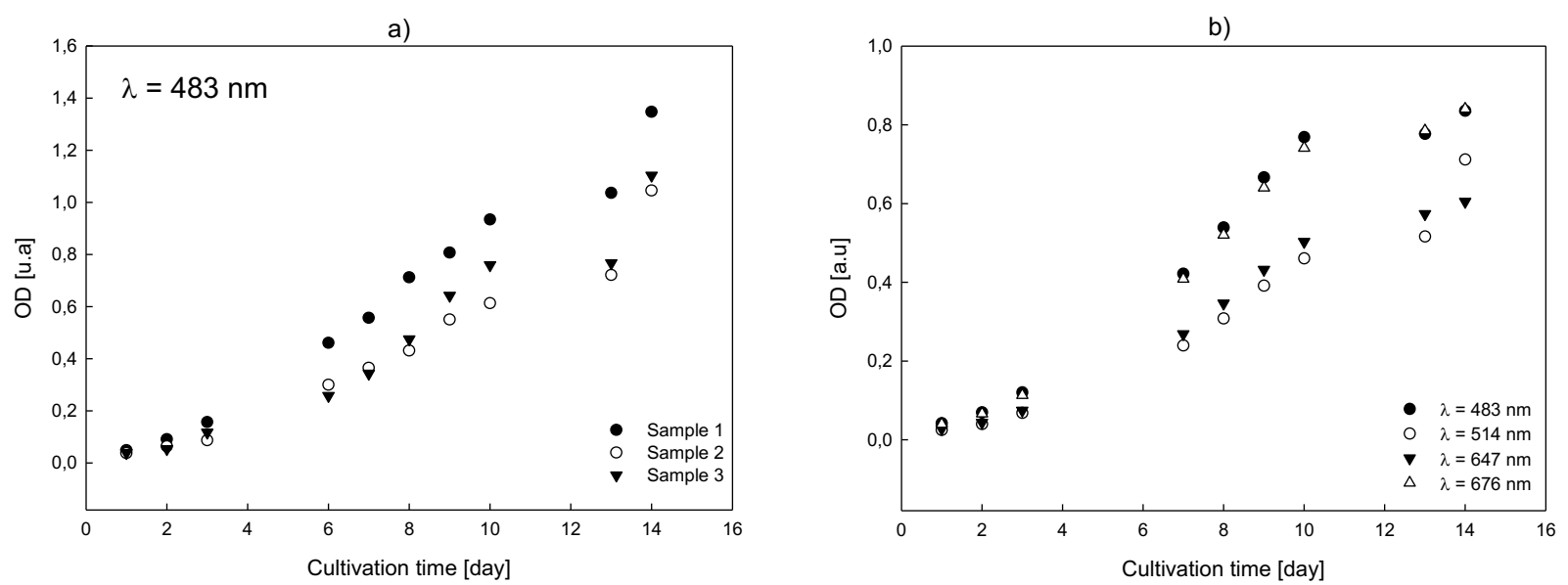

Fig. 3. Daily variation of Optical Density (measured in spectrometer): a) for the three samples at $\lambda=483 \mathrm{~nm}$. b) Mean Optical Density for each wave length.

The temporal evolutions of the OD, average of the three samples and for the four wavelengths of interest are shown in Fig. 3 b). The behavior of this measurement versus time shows a similar trend for the four wavelengths. However, their values are higher and very similar for $\lambda=483 \mathrm{~nm}$ and $\lambda=676 \mathrm{~nm}$ as expected since these wave lengths are closely to the absorption peaks of chlorophyll. 
In other hand, daily also for each sample, the THSP of dynamic speckle patterns at the selected wavelengths were registered and the normalized mean autocorrelation functions were calculate. In Fig. 4, the mean autocorrelation functions for the three samples corresponding to the third day analyzed are shown, with the abscissa unit corresponding to the time that the image processor requires to construct a THSP image, 20,5 s approximately.

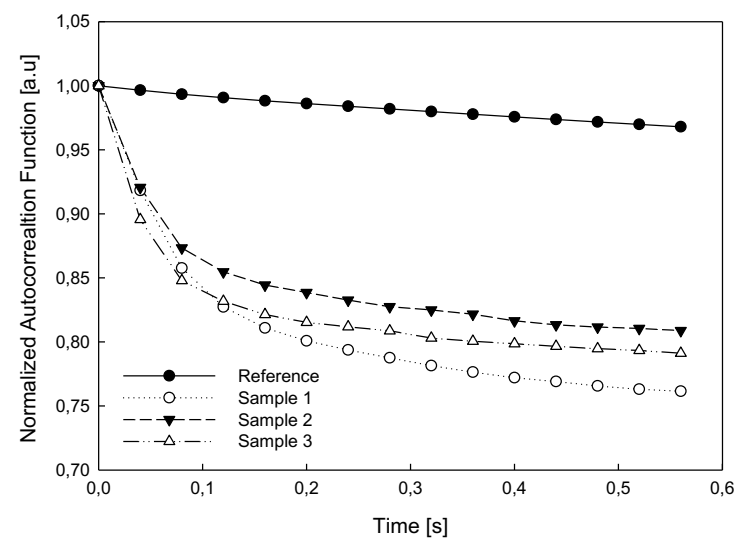

Fig. 4. Normalized autocorrelation functions corresponding to the third day.

Also, the mean autocorrelation function of dynamic speckle obtained from the sample of culture media without algae used as reference in the spectrometer determinations is shown. As the first few points of the autocorrelation show greater differences in the graphic, only The 15 first values are represented. As it is expected, for the reference sample the autocorrelation function tends to the autocorrelation function of a rectangle function, since the speckle pattern does not change in time.

Later on, each autocorrelation function was adjusted with according to eq. 1. From the adjustment it arises that the coefficient $b_{1}$ is superior in several magnitude order $\left(>10^{8}\right)$ to the others in the sum. In Fig. 5 a) it is show the data obtained for the three samples for $\lambda=483 \mathrm{~nm}$. Identical results were obtained for all selected wave lengths as it can be seen in Fig. 5 b) where the mean $b_{1}$ coefficient as a function of cultivation time for each wave length is plotted.

a)

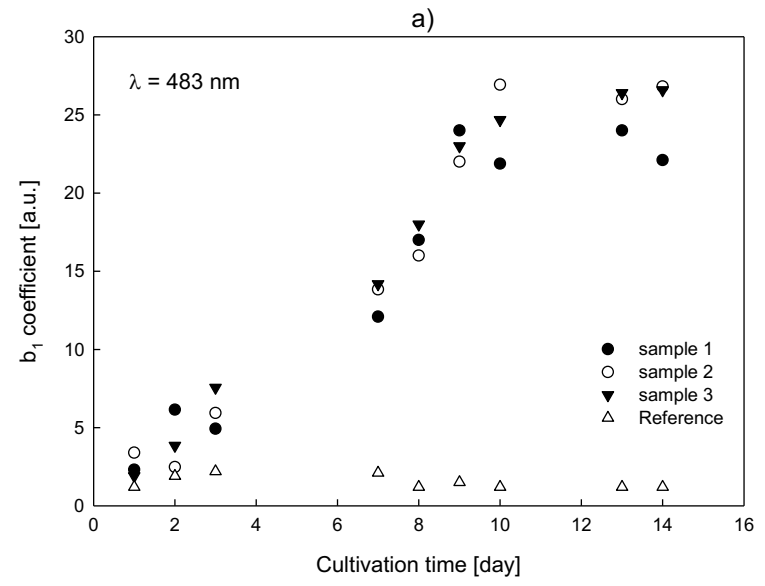

b)

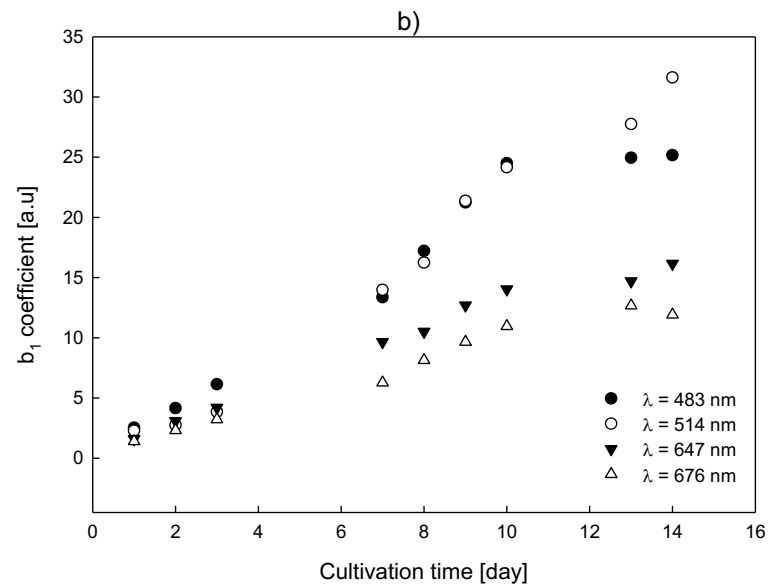

Fig. 5. Daily variation of $b_{1}$ coefficient: a) for the three samples at $\lambda=483 \mathrm{~nm}$. b) Mean $b_{1}$ coefficient for each wave length.

By comparing the figures $4 a$ ) and $5 a$ ), it can be seen that the daily variations of the coefficient $b_{1}$ and the OD have similar behavior. Another fact to consider in Figure 5 a) is that the activity of bio-speckle of the reference sample, although it has very small daily values varies with the culture time. This is explained by the fact that bio-speckle techniques yield global measurements of the behavior of scatterers within the sample. In this case, since BBM medium is a substance containing various salts, this means that the proposed non invasive measurement method it is able distinguish the presence of the small crystals in suspension. 
Values of $b_{1}$ coefficient and the corresponding measured by conventional method are compared in Fig. 6. A linear relation between both data with a high degree of correlation can be seen.
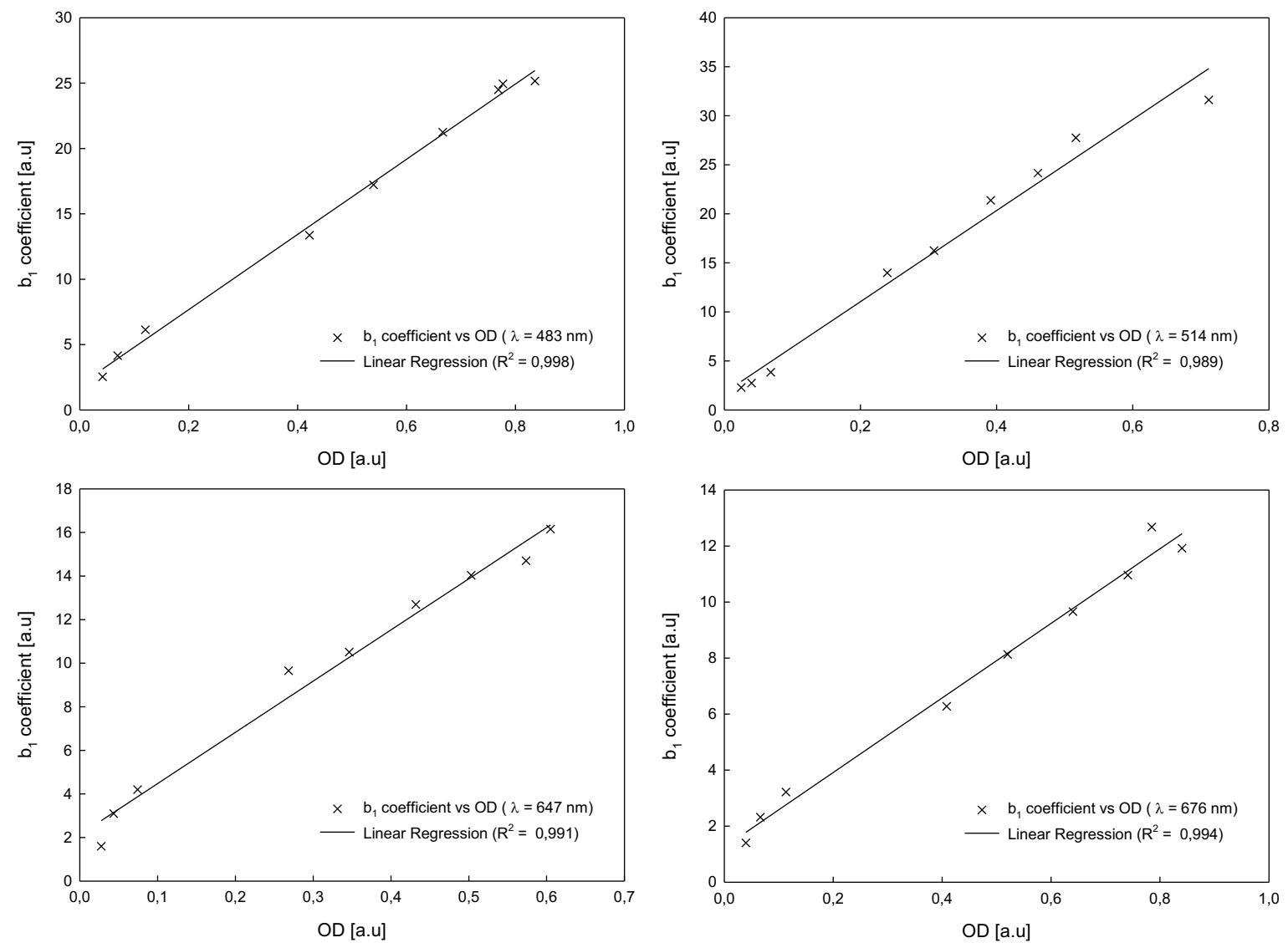

Fig 6. Correlation between $b_{1}$ coefficient and OD data for each selected wave length.

Once again, it can be seen that results correlate better for the wavelengths $\lambda=483$ and $\lambda=756 \mathrm{~nm}$. Being for $\lambda=514$ the minor correlation degree in accordance to the fact that green wave lengths are highly reflected by the algae.

\section{Conclusions}

It has been experimentally verified that bio-speckle technique is suitable for the analysis of algal population growth in four wave lengths. Values of the proposed parameter increase as a function of the time as the Optical Density measured with a commercial spectrophotometer does. The obtained results supported by the correlations between the data obtained by the standard technique and the proposed method and the simplicity of the experimental setup are encouraging and constitute a starting point to develop a noninvasive sensor, allowing the determination "in situ". The ultimate goal is to have a methodology that facilitates the daily monitoring without extracting the samples from the photobioreactor contributing to the development of bioreactors optimized for the production of microalgae on a large scale.

\section{Acknowledgements}

This work was supported by ANPCyT-PME,1392/2 and Research Council of the National University of Salta, Project no. 2161. 